\title{
BACK CHANNELS IN JAPANESE AND PORTUGUESE CONVERSATIONS: SYNTACTIC CONTEXT OF OCCURRENCE AND IMPLICATIONS FOR THE DYNAMICS OF INTERACTION ${ }^{1}$
}

RESUMO: No presente artigo analisamos a posição dos fáticos retroalimentadores em conversações em japonês e português, bem como as suas semelhanças e diferenças ao longo do processo interacional. Os fáticos retroalimentadores, apesar de ocorrerem em posições semelhantes na estrutura do discurso oral, apresentaram diferentes realizações sob a perspectiva interacional, sugerindo implicações significativas para o sistema conversacional de cada língua.

ABSTRACT: In this paper we analyze the position of back channels in Japanese and Portuguese conversations, as well as the similarities and differences between them in the course of interaction. Although in both languages back channels occurred in similar positions in the structure of spoken discourse, from the interactional point of view they showed different realizations, suggesting some significant implications for each exchange system.

PALAVRAS-CHAVE: fáticos retroalimentadores, interação, coordenação de ações, sintaxe discursiva.

KEYWORDS: back channels, interaction, conversation management, discourse syntax.

1. This paper is based on research completed as partial fulfillment for the Ph.D. requirements at Nagoya University, Japan.

2. Ph. D. candidate of Dept. of International Communication, Graduate School of International Development, Nagoya University. 


\section{Introduction}

Several researchers agree that conversation is an interactional achievement. In order to structure spoken discourse both speaker and hearer participate in conversation according to some rules determined by socio-cultural knowledge in combination with one's individual cognitive and linguistic skills. Back channel behavior, among other factors that contribute to the management of conversation, has been studied by many researchers, from several perspectives (Horiguchi, 1988: pp. 31-39). A search of the literature in either Japanese or Portuguese found that parallel investigations by either Japanese or Brazilian researchers focusing on the position of back channels within the structure of conversation have demonstrated regularities in the syntactic context in which they are produced in the course of the ongoing talk (Mizutani, 1988: pp. 4-11; Maynard, 1987: pp. 90-91; Urbano, 1996: pp. 12-16). However, no studies providing a contrastive description of back channel behavior in these languages were found. In the present paper, we first report on a preliminary study of the position of back channels in Japanese and Portuguese conversations. In the second part, we discuss the similarities and differences between them within the process of interaction as well as some implications for each speech exchange system.

\section{Scope and Manner of Investigation}

In order to investigate in which syntactic context back channels are usually produced, we examined their occurrence in transcribed conversations of TV programs, collected in Japan and in Brazil. The programs chosen were, respectively, Tetsuko no heya "Tetsuko's room" and Juca Kfouri. In both programs there is an interviewer who interacts face-to-face with a guest, in a television studio. Among several video-taped programs, we chose 14 dialogues in Japanese and 14 in Portuguese, and transcribed 5 minutes of each conversation. In order to keep the similarity between the data of both languages, we restricted the dialogues to those in which there were participants - native speakers of either Japanese or Portuguese - between 30 and 60 years of age.

The data were analyzed both quantitatively and qualitatively, according to the theoretical framework of Conversation Analysis.

\section{Back Channels in Japanese Conversation}

For the purpose of our study, we limited the object of analysis to non-lexical back channels such as uhn, ahn, uhn uhn and the like, and determined their occurrence in relation to the speaker's turn. As a result, we observed that back channels basically occurred in turn-final position and within turns. In the latter case, back channels occurred either "inserted" in or simultaneous to the speaker's utterance. The following table illustrates the back channels according to their position and percentage of occurrence. 
Table 1

\begin{tabular}{|c|c|c|c|}
\hline \multicolumn{2}{|c|}{ Syntactic context of occurrence } & $\begin{array}{l}\text { Number of } \\
\text { occurrences }\end{array}$ & $\%$ \\
\hline \multicolumn{2}{|l|}{ Turn-final } & 08 & 6.0 \\
\hline \multirow[t]{3}{*}{ Within-turn } & a) "inserted" in the speaker's turn & 79 & 59.4 \\
\hline & b) speech overlap & 46 & 34.6 \\
\hline & (total) & 133 & 100.0 \\
\hline
\end{tabular}

Back channels in turn-final position refer to those produced just after the completion of the speaker's turn, before the hearer starts his/her own utterance. For example ${ }^{3}$ :

Ex. $1 \quad\left(\right.$ Dialogue 9) ${ }^{4}$

G9: sôdesu $\downarrow$ ato ano bangumi no naka no sônyûka toka iwayuru hotondo jibun Tachi de hotondo $\rightarrow$

H1: $\underline{\text { he }} \uparrow$ demo ano kodomo ga ano miteru kodomo tachi ga ne $\uparrow$ (G9: hai) anata no ongaku ga suki datte

G9: yes $\downarrow$ besides that ahn the songs introduced during the program

Practically we ourselves practically $\rightarrow$

$\mathrm{H} 1: \underline{\mathrm{BC}} \uparrow$ but ahn the children ahn the children that watch it you know $\uparrow$ (G9: yes) (say that) they like your songs

In the dialogue above, the hearer, surprised to know that the songs played in a puppet show are composed by a band whose leader is the speaker G9 himself, produces a back channel of surprise ( $h \hat{e} \uparrow$ ). After that she starts her own speech, giving her comments about the success of G9's songs among children. Only 08 back channels occurred in this kind of context, which we will discuss later, when we analyze Portuguese dialogues.

Back channels occurring within turns, 'inserted' in the speaker's ongoing talk, can be seen in the example below:

\section{Ex. 2 (Dialogue 2)}

G2: de sore wo kattobashiki ikkyû te iu nowa $\uparrow$ jibun ni totte mâ tanka sono mono kamo shirenai shi $\uparrow(H 1: \underline{u h n})$ aruiwa hitotsu no ren'ai kamo shirenai shi $\downarrow$ (Hl: $\underline{\mathrm{uhn}})$ mâ iron na fû ni toreru uta dato omoundesukedomo $\downarrow$

G2: and the "balloon that exploded" that for me it may be the tanka itself (CC) $\uparrow$ $(\mathrm{H1}: \underline{\mathrm{BC}})$ or it may be a romance $(\mathrm{CC}) \uparrow(\mathrm{H1}: \underline{\mathrm{BC}})$ well I think it can be interpreted in many ways $\downarrow$

3. When translating the data from Japanese into English we considered both the semantic and the syntactic aspects.

4. Table of symbols used in the transcriptions on page 31 . 
Here, the speaker is explaining about the tanka (Japanese poem of 31 syllables) she has composed, and during her explanation, the hearer produced two back channels after the setsuzokujoshi shi (an additive clause connector), when the speaker produced brief pauses.

Other occurrences, including the example above, revealed that back channels occurring within turns were regularly distributed in specific syntactic contexts, that is, they tended to be produced in inter-sentential and intra-sentential positions. In the former case, back channels occurred in the sentence boundary position, usually following setsuzokujoshi "clause connectors" or shûjoshi "final morphemes" which are elements that come at the end of a clause or sentence. In the latter case, although some back channels occurred near joshi "auxiliary elements" (that occur postponed to words determining their syntactic and discoursive function), no clear evidence from the syntactic point of view could be found to explain such occurrence. Of 79 back channels occurring within turns, 58 occurred in an inter-sentential position and 21 in an intra-sentential context.

Finally, back channels that occurred simultaneous with the speaker's utterance are of a kind shown below:

\section{Ex. 3 (Dialogue 5)}

G5: watashi wa ano yarô to omoeba amimonodemo nandemo dekirun desu kedo $\downarrow$ mô zenzen tanoshiku yatchau hô

H1: $\quad$ [ah sô

G5: nandesu kedo $\downarrow$ ikinari dete kichattan desuyo $\downarrow$

HI: $\quad$ luhn

G5: I well if I feel like doing something I can do anything knitting or whatever but $\downarrow$ absolutely I am the kind of person who can

H1: $\quad$ [oh really

G5: do things with pleasure but $\downarrow$ it started all of a sudden you know $\downarrow$ $\mathrm{H} 1$ : $\quad[\underline{B C}$

In the example above, the hearer produced the back channel simultaneous with $\mathrm{Hl}$ 's utterance. It is significant to observe that all simultaneous back channels occurred in similar syntactic contexts to those produced within turns, that is, close to the boundary of a clause or a sentence. Of 46 back channels that occurred simultaneous to the speaker's utterance, 26 occurred in inter-sentential position (near to setsuzokujoshi, shûjoshi or near to the end of a sentence without these markers) and 20 in intra-sentential position. In general, the speech overlap occurred either because the speaker did not produce a brief pause after the context theoretically signaling the proper place for the hearer's back channel, or because the hearer produced the back channel in advance, before the cues cited above.

One final observation about back channels in Japanese conversation refers to the number displayed in the data. Of the 133 back channels found in the data, 79 occurred within turns (59.4\%), 46 occurred simultaneous to the speaker's utterance (34.6\%) and only 08 occurred in turn-final position $(6.0 \%)$. This result can be supported by the findings of Mizutani (1988:08) who argues that the frequency of back channels near clause boundaries, usually marked by connectors like te "and" kedo "but" and kara 
"because" is very high. According to Mizutani, the linguistic unit that precedes the back channel consists of an average of 20 syllables. Considering such size as the unit of spoken language, she concludes that the structure of Japanese dialogue consists of turns, with back channels inserted regularly within them, functioning similarly to commas in written language. Therefore, the structure of dialogue in Japanese, according to Mizutani, takes the following shape:

$\mathrm{X}$ : te kara

$\mathrm{Y}: \quad(\mathrm{BC}) \quad(\mathrm{BC})$ kedo

\section{Back Channels in Portuguese Conversation}

Similar to the findings in the previous analysis, we also identified back channels occurring in turn-final position, within turns and simultaneous with the speaker's utterance, as illustrated in table 2.

Table 2

\begin{tabular}{|c|c|c|c|}
\hline \multicolumn{2}{|c|}{ Syntactic context of occurrence } & $\begin{array}{l}\text { Number of } \\
\text { occurrences }\end{array}$ & $\%$ \\
\hline \multicolumn{2}{|l|}{ Turn-final } & 02 & 1.4 \\
\hline \multirow[t]{2}{*}{ Within-turn } & a) "inserted" in the speaker's turn & 66 & 44.9 \\
\hline & b) speech overlap & 79 & 53.7 \\
\hline & (total) & 147 & 100.0 \\
\hline
\end{tabular}

One representative example of each case is presented belows:

Ex. 4 (Dialogue 6)

G6: é mas depois ele tornou público de que o único que ele quer que imite $\uparrow$ sou eu então anh (H2:ahn) recebi esse aval dele né $\uparrow$

H2: $\underline{\text { ahn }}$ mas porque que que $\rightarrow$ você suspeita que em algum momento possa não ter gostado de te ver imitando ele $\downarrow$

G6: yes but later he made it public that the only one he wants to imitate him $\uparrow$ is me so ahn (H2:ahn) I received his permission you see $\uparrow$

$\mathrm{H} 2:$ BC but why do do $\rightarrow$ you suspect that in any moment (he) might have not liked to see you imitating him $\downarrow$

In the example above, G6, who is an actor, is talking about the permission he received from a well-known designer in Brazil to imitate him. Just after the speaker's utterance recebi esse aval dele né $\uparrow$ the hearer produced the back channel ahn and then

5. Translations from Portuguese into English were done according to the same criteria used in the analysis of Japanese data (cf. footnote 2). 
started his speech. Only 02 back channels occurred in this kind of context. According to Urbano (1996: 19-20) the production of non-lexical back channels in between turns is low because such kind of back channels do not carry any meaning per se.

Back channels that occurred within a turn, as observed in the Japanese data, occurred in inter-sentential (as shown in the example below) and intra-sentential position.

\section{Ex. 5 (Dialogue 1)}

G1: eu não posso negar que aprendi a gostar de futebol de criança (H2: $\underline{\text { ahn }})$ vendo jogos pela televisão $\rightarrow$ ouvindo pelo rádio $\rightarrow$

G1: I cannot deny that I learned to enjoy soccer in my childhood (H2: $\underline{B C})$ watching the games on television $\rightarrow$ listening to the radio $\rightarrow$

In the example above, the hearer produced a back channel ahn between the sentences eu não posso negar que aprendi a gostar de futebol de criança and vendo jogos pela televisão. We observed that in general back channels in inter-sentential position were produced after a sentence unit accompanied or unaccompanied by expressions such as né?, sabe?, entende? (equivalent to "isn't it?" "you know?"), that ask for the hearer's attention because of their perlocutionary force. The occurrence of back channels in intra-sentential position could not be clearly explained from the perspective of syntax, but from a semantic point of view, we observed that they occurred when the speaker produced brief pauses while giving an explanation about some topic.

The following dialogue is an example of back channels that were produced simultaneous with the speaker's utterance. Here too, back channels were produced in similar contexts to those within turns, that is, near to a clause or a sentence boundary or near to expressions that demand the hearer's attention.

Ex. 6 (Dialogue 12)

G12: agora em cinqüenta e oito a gente já tinha passado pelo aprendizado Juca $\downarrow$ é este o ponto que quero chegar $\downarrow$ $H 2$ : lahn ahn

G12: now in fifty eight we had already gone through the experience Juca $\downarrow$ that is the point I want to reach $\downarrow$

$\mathrm{H} 2$ :

$[\underline{B C}$

If we now look at the numbers in table 2, we can observe that of the 147 back channels found, 79 overlapped with the speaker's utterance (53.7\%), 66 occurred within a turn-unit (44.9\%) and only 02 occurred in turn-final position (1.4\%). This result can be supported by the findings of other researchers that in Portuguese back channels usually occur simultaneous with the main message. According to Urbano (1996:15) back channels that occur simultaneous with the speaker's utterance have a high frequency. Urbano explains that such phenomenon is natural, since back channels function to "monitor the speaker and do not interfere in the main message. They are usually produced mechanically by the hearer near sentence boundaries or even in intra-sentential position" 
(Urbano: 15). Similarly to Urbano, Marcuschi (1987:6) also states that the hearer response, such as back channels, "usually occurs in speech overlap"

In sum, based on the results of our analysis and on the findings of Mizutani who suggested a structure of dialogue in Japanese, which was previously presented, the structure of dialogue in Portuguese can be represented as follows:

$\mathrm{X}:$

$\mathrm{Y}$

(BC)

\section{Contrastive Discussion on Back Channels in Japanese and Portuguese Conversations and the Implications for the Dynamics of Interaction}

According to our previous analysis we observed that in either Japanese or Portuguese conversations back channels were produced basically in three syntactic contexts: 1) turn-final position, 2) within turns and 3) simultaneous with the speaker's utterance. This result shows that in both languages:

1. there are some linguistic features produced by the speaker that consistently precedes the display of the hearer's back channel. In Japanese conversation back channels were usually produced after setsuzokujoshi, shûjoshi and sometimes after joshi. Similarly, in Portuguese conversation back channels tended to be produced in sentence postboundary position or near expressions such as né?, sabe?, entende?, that function similar to shûjoshi;

2. these linguistic expressions can be hypothesized to be cues to mark appropriate points in the interaction for a hearer's back channels;

3. from the perspective of syntax, the production of back channels in both languages are similar.

In spite of this similarity, from the perspective of interaction the number of occurrences of back channels proved that they have different realizations in the course of the ongoing talk. While in Japanese back channels tended to occur within turns $(59.4 \%)$, in Portuguese they tended to be produced simultaneous with the speaker's utterance $(53.7 \%)$.

This result can be supported by the findings of Mizutani (1980) and Matsuda (1988), who explain that the structure of conversation in Japanese such as seen above, with back channels 'inserted' regularly within the speaker's turn, reveals the consideration of both speaker and hearer towards each other. Mizutani (1980:278) states that this kind of back channel behavior is an "evidence of the participants intention to preserve a good human relationship" Similarly to Mizutani, Matsuda (1988:64) also stresses the importance of keeping the apparent harmony in human relationship when interacting with others in Japanese culture.

Based on our findings and on existing investigations focusing on this matter, we can conclude that back channels produced 'inserted' in the course of the speaker's utterance are evidence of the hearer's attention, consideration and willingness to cooperate, in order to keep the conversation going smoothly. 
On the other hand, a search of the literature in Portuguese found that speech overlap in Brazilian culture is an acceptable phenomena and evidence of a cooperative attitude by the hearer. According to Preti (1988: 229), simultaneous back channels function to express agreement, disagreement or at least attention towards the speaker's talk. In addition, Preti \& Urbano (1990: 122, 135) report that speech overlap, when brief, does not interfere in the flow of the conversation. According to them, "the occurrence of speech overlap is related to cultural factors" and in Brazilian culture simultaneous back channels are evidence that the hearer is participating actively in the conversation.

On the whole we can say that while in Japanese conversation back channels "inserted" in the course of the speaker's utterance demonstrate the hearer's cooperative attitude to participate in conversation, in Portuguese conversation simultaneous back channels function to express the hearer"s cooperation in order to accomplish spoken discourse. Such difference might have some significant implications especially for intercultural communication. As described in the "Introduction" since conversation is the result of coordinate actions by speaker and hearer, and different exchange systems have different sociosequential organization of participation in conversation, back channel behavior can be said to influence in the flow and accomplishment of the verbal interaction.

In the present study we first concentrated on back channels in Japanese and Portuguese conversations separately, and later proceeded with a contrastive investigation of these elements. Therefore, it is difficult to precise from our results to which extent and at what levels back channel behavior can interfere in intercultural communication, but we believe our preliminary results can serve as basis for further investigations.

\section{Conclusion}

In our study we observed that in either Japanese or Portuguese conversations back channels occur in similar syntactic positions, that are, in turn-final position and within turns near some linguistic features produced in the course of the speaker's talk. However, it is important to notice that these linguistic cues for the production of back channels are permissive, not coercive. The hearer is not obliged to respond in the back channel upon display of these cues.

From the perspective of interaction, in both languages back channels revealed to be evidence of the hearer's willingness to participate and cooperate for the successful achievement of conversation. However, in Japanese conversation back channels are usually produced 'inserted' in the speaker's talk while in Portuguese conversation they are produced simultaneous with the speaker's utterance.

In order to conclude our present study, we would like to point out some questions that are in need of further investigations. We concentrated our analysis to non-lexical back channels but others such as lexical expressions and non-verbal reactions are also present in face-to-face interaction contributing to the management of conversation. Notwithstanding its limitations, we believe that this study may offer some insights into other researches focusing on conversation. 
Symbols used in the transcription

- letters used to identify the participants:

$\mathrm{G} 1 \ldots \mathrm{G} 9=$ guest

$\mathrm{H} 1=$ host in Japanese dialogues

$\mathrm{H} 2=$ host in Portuguese dialogues

- markers of intonation:

$\uparrow \quad=$ raising intonation

$\downarrow \quad=$ falling intonation

$\rightarrow \quad=$ flat intonation

[ $\quad$ = speech overlap

back channels were underlined in the original transcriptions and represented by $B C$ (also underlined) in English translations

CC = clause connector

\section{References}

DUNCAN, Starkey Jr. \& FISKE, Donald W. Face-to-face interaction: research, methods, and theory. New Jersey, Lawrence Erlbaum Associates, 1977.

HORIGUCHI, Junko. "Aizuchi kenkyû no gendankai to kadai". Nihongogaku. Vol. 10, n. 10, 1988, pp. 31-41.

MARCUSCHI, Luís Antônio. "Marcadores Conversacionais do Português Brasileiro: Formas, Funções e Posições" In: Castilho, A. T. de (org.) Português Culto Falado no Brasil. Campinas, Unicamp, 1987, pp. 281-321.

MATSUDA, Yôko. "Taiwa no nihongo kyôikugaku - aizuchi ni kanren shite". Nihongogaku. Vol. 7, n. 13, 1988, pp. 59-66.

MAYNARD, Senko. "Nichibei kaiwa ni okeru aizuchi hyôgen" Gekkan gengo. Vol. 16, n. 11, 1987, pp. 88-92. . Kaiwa bunseki. Tokyo, Kuroshio, 1993.

MiZUTANI, Nobuko. "Nihongo kyôiku to hanashi kotoba no jittai" Kindaichi Haruhiko Hakase Koki Kinen Ronbunshû. Vol. 2, Tokyo, Sanseido, 1980, pp. 262-279. "Aizuchi ron" Nihongogaku. Vol. 12, n. 7, 1988, pp. 4-11.

PRETI, Dino. "A Língua Oral: A Sobreposição de Vozes como Elemento de Interação no Ato Conversacional" Estudos Lingüisticos XVI, 1988, pp. 229-236.

Preti, Dino \& Urbano, Hudinilson. "Sobreposição de Vozes numa Perspectiva Psicocultural e Interacional" In: PRETI, Dino \& URBANO, Hudinilson. A Linguagem Falada Culta na Cidade de São Paulo - Estudos, vol.4. São Paulo, T. A. Queiroz/Fapesp, 1990, pp. 99140.

SCHEGLOFF, Emanuel. "Discourse as an interactional achievement: some uses of 'uh-huh' and other things that come between sentences" In: TANNEN, Deborah (ed.) Georgetown University Round Table on Languages and Linguistics, Analyzing discourse: text and talk. Washington D. C., Georgetown University Press, 1982, pp. 71-93.

URBANO, Hudinilson. "Marcadores de orientação interacional" Paper presented at the $9^{\text {th }}$ National Meeting of Anpoll, June 02-06, 1996, João Pessoa. 
YNGVE, Victor H. "On getting a word in edgewise" In: CAMPBELl, A. et alii (ed.) Papers from the sixth regional meeting - Chicago Linguistics Society. Chicago,University of Chicago Linguistics Department, 1970, pp. 567-578.

Endereço para correspondência: 466-0821 Nagoya-shi Showa-ku Maeyama-cho 1-14 Dormitory Maeyama (C-207) Japan

E-mail: enishikito@hotmail.com 